\title{
Vigilância epidemiológica na aquicultura maranhense: uma abordagem sistemática
}

\author{
Epidemiological surveillance in aquaculture in Maranhão: a systematic approach \\ Vigilancia epidemiológica en acuicultura en maranhão: un enfoque sistemático
}

Recebido: 23/07/2021 | Revisado: 27/07/2021 | Aceito: 03/08/2021 | Publicado: 08/08/2021

\author{
Anna Karoline Amaral de Souza \\ ORCID: https://orcid.org/0000-0001-8996-9309 \\ Universidade Estadual do Maranhão, Brasil \\ E-mail: annakarolasousa@gmail.com \\ Lauro de Queiróz Saraiva \\ ORCID: https://orcid.org/0000-0002-2509-6681 \\ Universidade Estadual do Maranhão, Brasil \\ E-mail: lauroqueirozaged@hotmail.com \\ Margarida Paula Carreira de Sá Prazeres \\ ORCID: https://orcid.org/0000-0001-6791-3718 \\ Universidade Estadual do Maranhão, Brasil \\ E-mail: guidaprazeres@ hotmail.com \\ Natan Anderson Lisboa Cunha \\ ORCID: https://orcid.org/0000-0002-6405-5620 \\ Universidade Estadual do Maranhão, Brasil \\ E-mail: natan.anderson.lisboa@ hotmail.com \\ Roberto Carlos Negreiros de Arruda \\ ORCID: https://orcid.org/0000-0003-2982-6052 \\ Universidade Estadual do Maranhão, Brasil \\ E-mail: rcnegreiros.arruda@gmail.com \\ Rosiane de Jesus Barros \\ ORCID: https://orcid.org/0000-0002-3198-6576 \\ Universidade Estadual do Maranhão, Brasil \\ E-mail: rosianejbarros@gmail.com \\ Danilo Cutrim Bezerra \\ ORCID: https://orcid.org/0000-0003-2075-9914 \\ Universidade Estadual do Maranhão, Brasil \\ E-mail: danilocbezerra15@gmail.com \\ Viviane Correa Silva Coimbra \\ ORCID: https://orcid.org/0000-0001-7611-6673 \\ Universidade Estadual do Maranhão, Brasil \\ E-mail: vivianecorrea@yahoo.com \\ Nancyleni Pinto Chaves Bezerra \\ ORCID: https://orcid.org/0000-0003-3970-7524 \\ Universidade Estadual do Maranhão, Brasil \\ E-mail: nancylenichaves@ hotmail.com
}

\begin{abstract}
Resumo
Objetivou-se com o estudo abordar de forma sistemática os aspectos relacionados à vigilância epidemiológica na aquicultura, perpassando por questões econômicas e regulatórias da atividade, focando nas ações executadas no estado do Maranhão. Para isso, realizou-se um levantamento bibliográfico a partir de fontes secundárias de pesquisa seguido da análise e interpretação das informações levantadas, de forma qualitativa. Com os procedimentos metodológicos adotados, constata-se que na produção brasileira em 2019, o estado do Maranhão foi o segundo maior em crescimento na produção de peixes de cultivo, o quinto maior produtor nacional neste quesito e o terceiro maior em produção de peixes nativos. A vigilância epidemiológica é reconhecida mundialmente como atividade fundamental para controle sanitário de explorações pecuárias. Para sua execução eficiente, esta necessita da participação comunitária associada às atividades desempenhadas pelos Serviços Veterinários Oficiais na rápida identificação, notificação e controle de enfermidades animais. No Brasil, há regulamentação para o controle sanitário de enfermidades de organismos aquáticos, porém, é escasso o registro de notificação destas. No Maranhão, estes dados inexistem, apesar da atividade aquícola ser relevante no estado e para a economia nacional. Como medidas propostas para reduzir os prejuízos da cadeia produtiva são necessárias ações de integração entre piscicultores, profissionais da iniciativa privada, instituições de pesquisa e agentes públicos em um esforço global para ampliar o universo sanitário, assim como melhorar o planejamento da produção visando o crescimento e consolidação da atividade tendo em conta a organização do setor e sua adequação para um futuro promissor.
\end{abstract}

Palavras-chave: Animais aquáticos; Regulamentação; Notificação de doenças; Sanidade animal. 


\begin{abstract}
The aim of the study was to systematically address aspects related to epidemiological surveillance in aquaculture, passing through economic and regulatory issues of the activity, focusing on the actions carried out in the state of Maranhão. For this, a bibliographic survey was carried out from secondary sources of research followed by the analysis and interpretation of the information collected, in a qualitative way. With the methodological procedures adopted, it appears that in Brazilian production in 2019, the state of Maranhão was the second largest in growth in the production of farmed fish, the fifth largest national producer in this regard and the third largest in production of native fish. Epidemiological surveillance is recognized worldwide as a fundamental activity for the sanitary control of livestock farms. For its efficient execution, it needs the community participation associated with the activities performed by the Official Veterinary Services in the rapid identification, notification and control of animal diseases. In Brazil, there are regulations for the sanitary control of diseases of aquatic organisms, however, there is little record of notification of these. In Maranhão, these data do not exist, despite the aquaculture activity being relevant in the state and for the national economy. As proposed measures to reduce losses in the production chain, integration actions are needed between fish farmers, private sector professionals, research institutions and public agents in a global effort to expand the health universe, as well as improve production planning aimed at growth and consolidation of the activity taking into account the organization of the sector and its suitability for a promising future.
\end{abstract}

Keywords: Aquatic animals; Regulation; Disease notification; Animal health.

\title{
Resumen
}

El objetivo del estudio fue abordar sistemáticamente aspectos relacionados con la vigilancia epidemiológica en la acuicultura, pasando por aspectos económicos y regulatorios de la actividad, centrándose en las acciones realizadas en el estado de Maranhão. Para ello, se realizó un relevamiento bibliográfico a partir de fuentes secundarias de investigación seguido del análisis e interpretación de la información recolectada, de forma cualitativa. Con los procedimientos metodológicos adoptados, parece que en la producción brasileña en 2019, el estado de Maranhão fue el segundo más grande en crecimiento en la producción de peces de cultivo, el quinto productor nacional en este sentido y el tercero en producción de peces nativos. La vigilancia epidemiológica es reconocida mundialmente como una actividad fundamental para el control sanitario de las explotaciones ganaderas. Para su eficiente ejecución, necesita de la participación comunitaria asociada a las actividades que realizan los Servicios Veterinarios Oficiales en la rápida identificación, notificación y control de enfermedades animales. En Brasil, existen regulaciones para el control sanitario de enfermedades de organismos acuáticos, sin embargo, hay pocos registros de notificación de estas. En Maranhão, estos datos no existen, a pesar de que la actividad acuícola es relevante en el estado y para la economía nacional. Como medidas propuestas para reducir pérdidas en la cadena productiva, se requieren acciones de integración entre piscicultores, profesionales del sector privado, instituciones de investigación y agentes públicos en un esfuerzo global por expandir el universo de la salud, así como mejorar la planificación productiva orientada al crecimiento y consolidación de la actividad teniendo en cuenta la organización del sector y su idoneidad para un futuro prometedor.

Palabras clave: Animales acuáticos; Regulación; Notificación de enfermedades; Salud animal.

\section{Introdução}

A população mundial cresce rapidamente e com ela, a necessidade por consumo de proteínas de elevado valor biológico, a exemplo da oriunda de animais aquáticos ${ }^{1}$ (Rodgers et al., 2015). A aquicultura e a pesca de forma integrada contribuem na produção de proteína, na geração de renda e como meio de subsistência para milhões de pessoas em todo o mundo (Santos, 2018).

A aquicultura, em especial, é uma atividade que pode ser realizada de forma tradicional, em pequena escala com pouca intervenção humana, assim como utilizar sofisticadas operações em que os animais são cultivados e gerenciados de forma a se obter ótimo desempenho e máxima produtividade. Dos ramos da aquicultura, a piscicultura se configura como uma importante fonte de proteína animal de elevado valor nutricional e o Brasil desponta como grande potencial para esta atividade produtiva, dado seu vasto território, clima propício para o crescimento de organismos cultivados e diversidade de espécies (Martins; Hipólito; Catroxo, 2011).

\footnotetext{
${ }^{1}$ Animais aquáticos: peixes, moluscos, crustáceos e outros animais destinados à aquicultura, em qualquer fase de seu desenvolvimento (Brasil, 2003).
} 
A natureza dos sistemas de produção na piscicultura (com intensificação contínua, dependência do comércio internacional, importância para meios de subsistência e segurança alimentar em países com recursos limitados) e suas práticas produtivas (com confinamento de espécies aquáticas em tanques com alta densidade populacional e introdução de espécies exóticas, sem os cuidados sanitários necessários) tornam-no propenso e extremamente sensível ao impacto e à propagação de doenças criando condições favoráveis à introdução e o desenvolvimento de micro-organismos e parasitas (Santiago et al., 2013; Brugere, Onuigbo \& Morgan, 2017).

Epidemias recorrentes e o surgimento de doenças emergentes em animais aquáticos são um grande desafio e representam constantes ameaças ao crescimento da aquicultura (Brugere, Onuigbo \& Morgan, 2017). Zhiming, et al. (2020) citam que nos últimos anos, as fazendas de peixes marinhos na China e nos países do Sudeste Asiático, áreas mais importantes do mundo em maricultura, sofreram frequentes perdas econômicas graves devido às ocorrências de doenças em peixes.

Para um sistema de vigilância eficaz é necessária a deteç̧ão rápida, com notificação representativa e diagnóstico preciso de doenças em animais. Neste processo, é fundamental compreender e considerar o papel da participação comunitária no processo de sustentação e efetivação de sistemas de vigilância, além dos fatores humanos que atuam na detecção e notificação de doenças. Dessa forma, a vigilância sindrômica pautada no agricultor pode atuar como uma alternativa para superar as limitações atuais da vigilância convencional de doenças e servir para demonstrar sua relevância para a aquicultura, particularmente em ambientes com recursos limitados (Brugere, Onuigbo \& Morgan, 2017).

A importância da vigilância epidemiológica para o controle sanitário de explorações pecuárias é reconhecido mundialmente. Porém, estas ações carecem de estruturação (recursos humanos - pessoal qualificado, financeiros e materiais) e participação ativa dos agentes envolvidos na atividade produtiva para a detecção e notificação de enfermidades como contribuição para o fortalecimento e execução a contento da vigilância e do controle de doenças infectocontagiosas.

Logo, este estudo tem relevância considerando a representatividade econômica que a atividade aquícola representa ao país e ao Maranhão, bem como pela necessidade de reconhecer quais instrumentos legais estão em vigor e alertar para a importância e finalidade da notificação no controle de doenças e na manutenção da sanidade dos animais aquáticos explorados no estado. Portanto, o trabalho se propõe a discutir aspectos relacionados à vigilância epidemiológica na aquicultura brasileira, perpassando por aspectos econômicos e regulatórios da atividade, com enfoque na atividade executado no estado do Maranhão.

\section{Metodologia}

O estudo apresenta abordagem qualitativa. Segundo Goldenberg (1997) citado por Gerhardt \& Silveira (2009), “a pesquisa qualitativa é voltada para a compreensão de um grupo social, sem a preocupação com representação numérica". Do ponto de vista dos procedimentos técnicos adotados, pode-se classificar a pesquisa em bibliográfica com a utilização de análise de literaturas específicas para a fundamentação teórico-metodológica. Bibliográfica, porque se realizou a leitura e análise crítica de artigos científicos, livros e legislações para a construção do arcabouço teórico do estudo. E quanto, ao problema investigado, a pesquisa apresenta natureza qualitativa com uma análise exploratória.

\section{Resultados e Discussão}

\section{Importância da produção de animais aquáticos no Brasil}

A pesca é uma atividade comercial praticada em mais de $8.500 \mathrm{Km}$ de costa do litoral brasileiro. É realizada na forma extrativa por diversos produtores e por agricultores familiares, apresentando elevada importância social e econômica para as regiões do país (Brasil, 2019a). Já a aquicultura é apontada como uma das atividades agropecuárias com maior potencial de 
crescimento na atualidade, de relevância sócio ambiental com premente benefício e valor estratégico em termos econômico e de segurança alimentar (Kirchner et al., 2016).

O Brasil, que já foi considerado o país com maior potencial para o desenvolvimento da pesca e aquicultura, tem papel de destaque em especial por sua disponibilidade hídrica, clima favorável e ocorrência natural de espécies aquáticas que compatibiliza interesse zootécnico e mercadológico (Brabo et al., 2016). Porém, apesar do amplo território e litoral, o Brasil ocupa, atualmente, a $13^{\mathrm{a}}$ posição na produção de peixes em cativeiro, e o $8^{\circ}$ na produção de peixes de água doce, apresentando um consumo médio de 9,5 $\mathrm{kg}$ de peixe por habitante/ano, ficando abaixo da média internacional que chega até 20,5 $\mathrm{Kg}$ por habitante/ano e do recomendado pela Organização Mundial da Saúde (OMS) que é de $12 \mathrm{Kg}$ por habitante/ano (Fogaça, 2020).

$\mathrm{Na}$ indústria alimentícia, os animais aquáticos são denominados tecnicamente de pescado, alimento com importância nutricional por apresentar quantidade e qualidade de proteínas, vitaminas e minerais, e principalmente, como fonte de ácidos graxos poli-insaturados essenciais ômega-3 - eicosapentaenoico (EPA) e docosaexaenoico (DHA). A orientação do seu consumo está associada à redução do risco e da ocorrência de doenças crônicas não transmissíveis e como garantia de funções importantes nas fases iniciais do desenvolvimento humano (Sartori \&Amancio, 2012).

O Brasil segue a tendência mundial na busca por alimentos saudáveis indicados para a saúde humana como forma de disponibilizar a população uma carne mais saudável e que mantenha alto valor proteico. Nos últimos anos, o crescimento da população mundial impulsionou a oferta e qualidade de produtos, com inúmeras variedades de pescado e produtos derivados semiacabados. No ano de 2018, foram produzidas 179 milhões de toneladas de pescado no mundo, com valor estimado em US\$ 401 bilhões (Alves, 2020), aproximadamente $87 \%$ da sua produção (156 milhões de toneladas) foi destinada ao consumo humano. Isto representa uma mudança significativa no uso do pescado desde a década de 1960, pois, anteriormente uma quantidade expressiva era utilizada na produção de farinha e óleo de peixe (Fogaça, 2020).

\section{Características da produção de animais aquáticos no Brasil}

Para Brabo et al. (2016), os ramos mais desenvolvidos da aquicultura brasileira são a piscicultura continental, a carcinicultura marinha e a malacocultura. Nos últimos anos, se observou o crescimento na produção da carcinicultura de água doce, ranicultura, algicultura e quelonicultura.

Segundo pesquisadores da Embrapa Pesca e Aquicultura do Tocantins, em dez anos (entre 2005 a 2015) houve crescimento de $123 \%$ na aquicultura brasileira, explicado por fatores como a chegada de novas empresas, rápida profissionalização e intensificação tecnológica da produção o que resultou no aumento de 257 mil para 574 mil toneladas de animais aquáticos nesse período (Brasil, 2017).

Segundo dados do Sistema de Informações Gerenciais do Serviço de Inspeção Federal (SIGSIF) do Ministério da Agricultura, Pecuária e Abastecimento (MAPA), obtidos em julho de 2019, pela distribuição de estabelecimentos de pescado sob SIF por área de atuação e Unidade da Federação (UF), contido no Anuário dos Programas de Controle de Alimentos de Origem Animal do Departamento de Inspeção de Produtos de Origem Animal (DIPOA), dos 299 estabelecimentos registrados, o Maranhão possui apenas um (Brasil, 2019b).

Há poucos estudos com a descrição da produção de animais aquáticos no estado do Maranhão. Em estudo para caracterização da frota pesqueira do litoral maranhense Ocidental, Golfão e litoral Oriental, Almeida, Ferreira \& Nahum (2006) identificaram dez tipos de embarcações utilizadas por pescadores: o Cúter, Bote, Bianas, Igarité, Boião, Casquinho, Catamarã, MAR, Lagosteiros e Pargueiros. Neste estudo, constataram, ainda, que o número das embarcações evoluiu ao longo dos anos, totalizando 7.114 à época, com predominância para as embarcações à remo, seguido daquelas à vela. Para estes autores, o processo de motorização da frota na costa maranhense implicaria em um aumento geral do poder das capturas. 
Já em 2007, Almeida e colaboradores ao observar o Sistema de Produção Pesqueira do Peixe serra (SPP-serra) no município da Raposa/MA, composta por 359 embarcações ativas, responsáveis por 12\% da produção anual de pescado do litoral maranhense, constataram a utilização de rede de emalhar do tipo serreira como arte de pesca e embarcações de grande porte, que conferia autonomia de 15 dias de pesca. Atestaram ainda, que embora apresentassem escolaridade e renda baixas, com uma organização social reduzida e fragmentada, os pescadores demonstraram percepção ambiental e etnoconhecimento satisfatórios em relação à espécie capturada e que o pescado era resfriado com destino para as cidades de São Luís, Fortaleza e Recife, onde era comercializado para posterior beneficiamento.

\section{Perspectivas da produção de animais aquáticos no Brasil}

O consumo global de pescado (soma da pesca e aquicultura) cresceu 3,1\% na média anual de 1961 para 2018, representando quase o dobro do crescimento da população, sendo mais alta que todas as outras proteínas de origem animal (bovina, suína, aves, leite, ovos etc.). O consumo per capita nesse período apresentou média anual de crescimento próxima de $1,5 \%$ ao ano (Alves, 2020).

De acordo com os dados divulgados no Anuário 2020 da Associação Brasileira da Piscicultura, em 2019, a produção de pescado no Brasil aumentou 4,9\% e atingiu 758.006 t, com receita em média $\mathrm{R} \$ 5,6$ bilhões. Um mercado que gera em torno de um milhão de empregos diretos e indiretos. O país se destacou em produção de tilápia com 432.149 t, ocupando a quarta posição mundial e representando $57 \%$ da produção nacional. Porém, no Maranhão, o cultivo desta espécie representou menos de 10\% do total de pescado do estado, com uma produção de 4.019 t (Peixe BR, 2020a).

A produção de peixes nativos (tambaqui, tambatinga, curimatã) no mesmo período foi diferente, com resultado alcançando 38\% na produção total, o que representou um recuo de quase dois pontos percentuais em relação aos 39,84\% de 2018. Entre os estados produtores, Rondônia manteve-se na liderança no segmento de peixes nativos de cultivo; já o estado do Maranhão, se destacou na $3^{\mathrm{a}}$ posição, com $38.511 \mathrm{t}$, impulsionado pelo aumento de 9,4\% na produção de nativos (Peixe BR, 2020a).

Já outros peixes de cultivo (carpas, truta e panga) representaram uma surpresa no desempenho da piscicultura brasileira em 2019, principalmente a atuação da espécie Pangasianodon hypophthalmus (Sauvage, 1878), popularmente conhecido como Pangasius ou simplesmente peixe Panga, recém-chegada ao país, que ganhou relevância em alguns estados do Nordeste. Neste ano, o Maranhão produziu $2.470 \mathrm{t}$ de peixes de cultivo, ficando em $5^{\mathrm{a}}$ posição de produção nacional (Peixe BR, 2020a).

Em 2019, a piscicultura, foi o segundo mais importante segmento das exportações de pescado do Brasil, faturando quase US\$ 12 milhões (4\% do total). Neste ano, o total de pescado exportado gerou US\$ 275 milhões e as exportações desta atividade e de seus subprodutos apresentou crescimento $26 \%$ em relação ao ano anterior, passando de $5.185 \mathrm{t}$ para $6.543 \mathrm{t}$. Entre os anos de 2015 a 2019, as exportações da piscicultura brasileira apresentaram crescimento de $833 \%$, partindo de $701 \mathrm{t}$ para $6.543 \mathrm{t}$ (Peixe BR, 2020b).

O SARS-CoV-2, agente etiológico da Covid-19 mudou o mundo e a pandemia afetou diretamente todas as áreas de produção, em maior ou menor grau. Isto também aconteceu com o fornecimento de pescado para alimentação. O Brasil, conhecido como o país do Agro, responsável pela alimentação de boa parte da população do planeta, com produção e exportação de grãos e proteínas de origem animal, também exporta pescado oriundo da pesca, apresentando uma produção competitiva em muitos mercados, porém alguns negócios foram fechados no início do ano de 2020, principalmente de explorações de tilápias e camarões (Alves, 2020). 
Nesse atual cenário de pandemia, a aquicultura pode apresentar papel ainda mais importante, principalmente, ao considerar o potencial da atividade para o crescimento no mercado doméstico, que se encontra limitado à oferta de produtos, assim como as oportunidades para ampliação das exportações (Alves, 2020).

Já no primeiro trimestre de 2020 as exportações da piscicultura (peixes e seus subprodutos) totalizaram 1.635 t, volume que representa aumento de $42,67 \%$ comparado com o mesmo período de 2019 , onde foram exportadas 1.146 t. O crescimento gradativo na produção teve no mês de março o maior volume com 576 t (Pedroza \& Rocha, 2020).

\section{Estrutura governamental para vigilância epidemiológica em animais aquáticos}

O primeiro Programa Nacional de Sanidade de Animais Aquáticos (PNSAA), foi estabelecido pelo Ministério da Agricultura Pecuária e Abastecimento - MAPA por meio da Portaria № 573, de 4 de junho de 2003, com o fim de regulamentar a produção de animais aquáticos no país. O seu Regulamento Técnico foi aprovado em 2 de julho de 2003, por meio da Instrução Normativa (IN) $\mathrm{N}^{\circ} 53$, que padronizou as ações profiláticas, métodos de diagnósticos e o saneamento dos estabelecimentos de aquicultura, cabendo às instâncias intermediárias e locais do Sistema Unificado de Atenção à Sanidade Agropecuária (SUASA) a execução das ações previstas e a aplicação das sanções quando do não cumprimento da norma (Brasil, 2003).

Cabe ao Departamento de Defesa Animal (DDA) a coordenação das medidas de prevenção das doenças no intuito de impedir a introdução de doenças exóticas e controlar ou erradicar as existentes no território nacional, assim como controlar o trânsito internacional de animais aquáticos. Enquanto, às instâncias intermediárias e locais do SUASA, cabe a execução das ações de cadastramento, fiscalização e vigilância dos estabelecimentos, assim como o controle de trânsito dos organismos aquáticos dentro do país, aplicação de sanções quando do não cumprimento da norma e atendimentos às notificações de doenças (Brasil, 2003; Brasil, 2015a).

Os Órgãos Executores de Sanidade Agropecuária (OESA) também deverão instituir Comitês Estaduais de Sanidade de Animais Aquáticos de caráter consultivo e com a representação do setor produtivo e de órgãos oficiais relacionados às atividades de sanidade pesqueira e aquícola (Brasil, 2015a).

\section{Programas sanitários}

Com o sucessivo crescimento da população humana global e a demanda progressiva por proteína alimentar, a proteína animal aquática tornou-se um recurso cada vez mais importante. Em várias áreas geográficas, os estoques foram severamente demandados na pesca. Em resposta, a produção da aquicultura aumentou nos últimos 30 anos (Oidtmann et al., 2011).

A Organização Mundial da Saúde Animal (OIE) possui as orientações básicas no Código Sanitário para Animais Aquáticos (2019a) para o mundo moderno, em que trata da prevenção e controle das enfermidades por meio da zonificação e compartimentação, desinfecção de estabelecimento e equipamentos de aquicultura, elaboração de um plano de emergência, vazios sanitário, manipulação, eliminação e tratamento de resíduos de animais aquáticos e controle dos agentes patogênicos nas rações.

O Programa Nacional de Sanidade de Animais Aquáticos de Cultivo - "Aquicultura com sanidade", foi institucionalizado pela IN $\mathrm{n}^{\circ}$ 04, de 04 de fevereiro de 2015, em substituição a IN $\mathrm{n}^{\circ} 18$, de 13 de maio de 2008, e posteriormente alterada pela a IN $\mathrm{n}^{\circ} 4$, de 28 de fevereiro de 2019. O PNSAA tem por finalidade garantir a sustentabilidade dos sistemas de produção, com normativas direcionadas à prevenção, controle e erradicação de doenças dos cultivos nacionais. Como referência a procedimentos e processo de diagnóstico de enfermidades em animais aquáticos, no Art. 101 da IN ${ }^{\circ}$ 4/2019, consta que a coleta e remessa das amostras laboratoriais para confirmação de doenças são de responsabilidade do Serviço Veterinário Oficial (SVO) ou de médico veterinário a realizar coleta e remessa de amostras oficiais para laboratórios 
da Rede Federal de Laboratórios de Defesa Agropecuária, por meio dos Laboratórios de Pesca e Aquicultura (RENAQUA) e laboratórios credenciados públicos e privados" (Brasil, 2019c).

Segundo o Art. $2^{\circ}$ da IN n ${ }^{\circ}$ 3, de 13 de abril de 2012 são integrantes da RENAQUA: o extinto Ministério da Pesca e Aquicultura (MPA), os Laboratórios Oficiais Centrais (AQUACENS), os Laboratórios Oficiais (LAQUAS), e os Laboratórios Credenciados, que oferece suporte ao diagnóstico oficial de doenças de peixes de produção, incluindo espécies nativas, peixes ornamentais, moluscos, quelônios, répteis, anfíbios e crustáceos para o abastecimento do mercado interno e externo. O Art. $3^{\circ}$ desta instrução esclarece que foram instituídos dois AQUACENS classificados de acordo com seu escopo analítico: o Saúde Animal (laboratório oficial central responsável pelas metodologias analíticas em doenças de animais aquáticos e o Resíduos) e Contaminantes (laboratório oficial central responsável pelas metodologias analíticas em resíduos e contaminantes de recursos pesqueiros) (Brasil, 2012).

Amostras oficiais são coletadas por servidores públicos que atuam na inspeção federal com objetivo de analisar a conformidade dos produtos de origem animal em relação aos aspectos de inocuidade, identidade e qualidade. As análises fiscais são realizadas pelos Laboratórios Federais de Defesa Agropecuária (LFDA), laboratórios próprios do MAPA. Em 2018, amostras de produtos da pesca e aquicultura de estabelecimentos nacionais sob inspeção oficial e também de produtos importados foram coletadas a partir de estabelecimentos nacionais sob inspeção oficial em 12 estados e no Distrito Federal, em atendimento ao Subprograma de Controle Oficial da Fraude por Substituição de Espécies de Pescado. Assim, foram analisadas 140 amostras de pescado, em que 56,4\% destas foram produzidas por estabelecimentos nacionais sob Inspeção Federal; 27,1\% foram produzidas em estabelecimentos sob Inspeção Estadual; 15,7\% produzidas em estabelecimentos estrangeiros e 0,7\% em estabelecimentos sob Inspeção Municipal. As amostras coletadas nesta operação ocorreram em embalagens de Sardinha substituídas por Sardinha-Lage; Pescada Amarela, Pescada-Branca e Robalo substituídos por Pescada Cambucu ou outra Pescada; Pescada Cambucu substituída por Pescada-Dentão; Maria-Luíza substituída por Abrótea; Cavala-Branca substituída por Cavala-Verdadeira; Surubim substituído por Bagre; Bacalhau (Gadus Morhua) substituído por Polaca do Alasca; Linguado substituído por Pangasius e Alabote Dente-Curvo; Merluza substituída por Abrótea (Brasil, 2019b).

Algumas não conformidades observadas em produtos de origem animal nas amostras de peixe congelado coletadas no Programa de Avaliação de Conformidade de Produtos de Origem Animal Comestíveis (PACPOA) de importados em 2018 foram: a Escherichia coli em Filé de Panga do Vietnã; Sódio acima do limite máximo estabelecido pela IN no 21/2017; presença de polifosfatos em Filé de Merluza da Argentina; e, sódio acima do limite máximo estabelecido na Sardinha do Marrocos (Brasil, 2019b).

Para a modernização da atividade, se faz necessários investimentos em plantas de processamento, desenvolvimento de novos produtos, controle sanitário, logística e licenciamento ambiental, bem como intensificar as parcerias entre a iniciativa privada e o setor público, incluindo os governos municipais, estaduais e federal, com destaque ao papel da Embrapa Pesca e Aquicultura e da Secretaria de Aquicultura e Pesca do MAPA no processo (Peixe BR, 2020c).

No Maranhão, a Sanidade dos Animais Aquáticos está a cargo da Agência Estadual de Defesa Agropecuária do Maranhão (AGED-MA), com ações direcionadas à promoção da sanidade de peixes, crustáceos, anfíbios e moluscos, visando à prevenção, controle e erradicação de doenças nos sistemas de produção de animais aquáticos, pela busca de um sistema de vigilância ativo, iniciado pelo cadastro de estabelecimentos e piscicultores (Maranhão, 2020a).

Em 2015, a AGED-MA criou o Setor de Sanidade dos Animais Aquáticos com o objetivo de implantar no estado do Maranhão, o Programa Nacional de Sanidade dos Animais Aquáticos de Cultivo - Aquicultura com Sanidade, instituído por meio da IN nº/2015 e da Portaria MPA nº 19/2015 (Maranhão, 2016a). Atualmente, este setor está estruturado, com um responsável técnico pela coordenação a nível central, com dedicação exclusiva ao programa, para elaboração do planejamento e acompanhamento das ações a ser executadas no estado. Dentre as principais ações executadas estão: promoção da sanidade 
dos animais aquáticos (peixes, crustáceos, anfíbios, moluscos); definição das ações que visam à prevenção, controle e erradicação de doenças nos sistemas de produção de animais aquáticos; cadastramento dos estabelecimentos que cultivam ou mantém animais aquáticos; implantação e manutenção do sistema de vigilância ativa para monitoramento e controle de doenças de notificação obrigatória (Maranhão, 2020a).

\section{Agentes de vigilância epidemiológica}

No que se refere à vigilância epidemiológica de animais aquáticos, a base do serviço veterinário brasileiro apresenta diversas dificuldades. Os profissionais responsáveis pela defesa sanitária animal apresentam amplo conhecimento na área de animais terrestres, inversamente proporcional a familiaridade com os animais aquáticos. Apesar da estrutura formal de defesa sanitária animal, os serviços oficiais de saúde dos animais aquáticos necessitam de melhor capacitação em relação às ações que visem o controle de doenças desses animais (Maciel \& Maciel, 2011).

O MPA, criado em 2009, instituiu a RENAQUA e a Rede de Colaboração em Epidemiologia Veterinária (AQUAEPI) para fornecer suporte laboratorial e de inteligência epidemiológica, fundamentais para as ações de monitoramento, controle e vigilância de animais aquáticos (Brasil, 2013a).

Hoje, reformulado e intitulado por Secretaria de Aquicultura e Pesca (SAP/MAPA), o MPA, estabeleceu normas para habilitação de profissionais que atuam no setor privado, para a realização de coleta e remessa de amostras oficiais para laboratórios do RENAQUA, para fins de execução de atividades de defesa sanitária de animais aquáticos, por meio da IN $\mathrm{n}^{\circ}$ 26, de 12 de novembro de 2014 (Brasil, 2014a).

Cabe aos agentes do OESA em cada Estado auditar, ao menos uma vez ao ano, todas as unidades de quarentena, os estabelecimentos de aquicultura que produzem e transportam formas jovens de animais aquáticos e outros estabelecimentos de aquicultura considerados de maior risco sanitário em decorrência de suas características epidemiológicas. Os demais estabelecimentos de aquicultura deverão ser auditados ao menos uma vez a cada três anos (Brasil, 2015a).

\section{Notificação de doença}

Doença pode ser definida como a alteração biológica do estado de saúde de um ser (homem, animal etc.), manifestada por um conjunto de sintomas perceptíveis ou não (Brugere, Onuigbo \& Morgan, 2017). As doenças comprometem profundamente o bom desempenho zootécnico dos animais, causando prejuízos consideráveis ao piscicultor (Leira et al., 2017).

O Brasil é signatário das normas sanitárias expedidas pela OIE, que estabelece para a notificação de um evento, a necessária indicação das espécies hospedeiras, número e a distribuição geográfica dos animais aquáticos afetados e as unidades epidemiológicas afetadas. Determina, ainda, que a detecção do agente patogênico de uma enfermidade em um animal aquático deverá ser notificada inclusive na ausência de sinais clínicos, pois considera que a relação agente patogênico - enfermidade clínica permanece em constante evolução e que a presença de um agente infeccioso não implica necessariamente na presença clínica de uma enfermidade (OIE, 2019b).

A partir das notificações, os países signatários da OIE deverão informar quais providências são adotadas para prevenir a propagação das enfermidades, como medidas de quarentena e restrições aplicadas à movimentação dos animais aquáticos, produtos de animais aquáticos, produtos biológicos e objetos diversos, que por sua natureza, podem ser responsáveis pela transmissão de enfermidades. No caso de enfermidades transmitidas por vetores, devem ser indicadas, também, as medidas adotadas para seu controle (OIE, 2019b). 
No Brasil, as enfermidades de animais aquáticos passíveis de notificação obrigatória ao SVO estão definidas na Portaria No 19, de 04 de fevereiro de 2015, do MPA. No anexo desta Portaria consta a relação de enfermidades que acometem peixes (27 doenças), crustáceos (20 doenças), moluscos (seis doenças) e anfíbios (duas doenças) (Brasil, 2015a).

Já a IN nº 04, de 04 de fevereiro de 2015, apresenta orientações para a notificação da suspeita ou ocorrência de doença de notificação obrigatória, que é compulsória para qualquer cidadão, bem como para todo profissional que atue na área de diagnóstico, ensino ou pesquisa em saúde animal (Brasil, 2015a). A IN n ${ }^{\circ}$ 04, de 28 de fevereiro de 2019, alterou do MPA ao MAPA, a responsabilidade pela publicação da lista de doenças de notificação obrigatória ao SVO por meio de ato legal complementar (Brasil, 2019d).

A notificação obrigatória de suspeita ou ocorrência de qualquer doença ou de nova cepa de agente patogênico deverá ser realizada imediatamente, no prazo máximo de 24 horas de seu conhecimento quando ocorrer: a) pela primeira vez ou reaparecer em área (país, região, unidade federativa, zona ou compartimento) declarada oficialmente livre; b) mudança repentina e inesperada nos parâmetros epidemiológicos como distribuição, incidência, morbidade ou mortalidade de uma doença que ocorre no país, região, unidade federativa, zona ou compartimento; ou, c) mudança de perfil epidemiológico como mudança de hospedeiro, de patogenicidade ou surgimento de novas variantes ou cepas, principalmente se houver repercussões para a saúde pública (Brasil, 2015a).

A notificação também deverá ser imediata para qualquer outra doença de animal aquático que não pertença à lista de doenças oficial quando se tratar de doença exótica ou de doença emergente que apresente índice de morbidade ou mortalidade significativo, ou que apresente repercussões para a saúde pública. Em caso de suspeita de doença ou na ocorrência de altas mortalidades sem causa conhecida, o SVO deverá ser imediatamente comunicado para a realização de investigação epidemiológica e adoção das medidas cabíveis em até 24 (vinte e quatro) horas após a notificação (Brasil, 2015a).

Uma das formas de se avaliar o sistema de vigilância de enfermidades é por meio da participação comunitária nas notificações de doenças ao SVO. Logo, é necessário o entendimento pela comunidade, da importância do relato sobre a ocorrência de doenças e de sua deteç̧ão precoce, assim como reconhecimento dos efeitos que a subnotificação provoca nos programas de controle de doenças (Halliday et al., 2012).

Diante disso, a permissão pelo SVO para identificação e relato de enfermidades por piscicultores não treinados, pode apresentar vantagens básicas para a vigilância sindrômica. Estas vantagens residem no fato de que os piscicultores não estão limitados pelo viés do conhecimento prévio da doença, como muitos profissionais capacitados ou agentes comunitários de saúde animal; além de sua proximidade da criação, suas habilidades observacionais em perceber desvios da norma e identificar sinais de doenças existentes e emergentes nos animais sob seus cuidados, podem gerar relatos precisos dos sinais de enfermidades óbvios, como aqueles apresentados pelas doenças mais ameaçadoras para a aquicultura (Brugere, Onuigbo Morgan \& 2017).

\section{Trânsito estadual de animais aquáticos}

Segundo Goes et al. (2017), em aquicultura, o transporte de animais é uma rotina de operação delicada e de alto risco, que demanda especial atenção, capacitação técnica da mão-de-obra e equipamentos específicos a fim de mitigar prejuízos. Além disso, a movimentação de animais aquáticos vivos, dentro e entre países, para a aquicultura e o comércio de ornamentais, implica em riscos e ganha importância como via de disseminação de agentes etiológicos (Oidtmann et al., 2011).

Com a IN n 4 , de 04 de fevereiro de 2015, para o transporte de animais aquáticos vivos, seu material de multiplicação e matéria-prima obtida de animais de cultivo deverá ser emitida a Guia de Trânsito Animal (GTA) (Brasil, 2014b; Brasil, 2015a; Freire et al., 2019). A emissão de GTA para animais aquáticos poderá ser realizada por médicos veterinários da instância central, intermediária e local do SUASA, independente de habilitação prévia, ou por demais servidores do OESA 
após treinamento específico e designação através de ato administrativo formal. Poderá ser concedida a habilitação para emissão da GTA aos médicos veterinários não vinculados ao SVO e responsável técnico do estabelecimento de aquicultura com formação profissional legalmente compatível com a natureza da certificação exigida para o transporte para estabelecimentos registrados em órgão oficial de inspeção ou para criatórios (Brasil, 2015a).

A nota fiscal do pescado proveniente da atividade de aquicultura não substitui a exigência de GTA para o transporte de matéria-prima de animais aquáticos para as indústrias beneficiadoras sob serviço de inspeção (Brasil, 2015a, 2019a).

O trânsito da matéria-prima proveniente da pesca para inspeção higiênico sanitária/processamento com inspeção veterinária oficial pode ser amparado pela nota fiscal do pescado que deverá apresentar o número de inscrição regular no Registro Geral da Atividade Pesqueira (RGP), na respectiva categoria, assim como o número de identificação de registro junto aos Serviços de Inspeção Oficial (Federal, Estadual ou Municipal) do estabelecimento de destino (Brasil, 2014c).

A emissão da GTA pode ser dispensada quando o transporte de animais aquáticos vivos para ornamentação e aquariofilia compreender o trecho entre o local de pesca e o primeiro ponto de comercialização; ou entre um comerciante e um consumidor final, desde que este último não exerça atividades pesqueiras com fins comerciais; quando se tratar de transporte de animais aquáticos importados com finalidade de alimentação animal com rotulagem aprovada pelo serviço de inspeção oficial ou transporte de animais aquáticos vivos, seu material de multiplicação e matéria-prima com finalidade de diagnóstico nos laboratórios da RENAQUA (Brasil, 2014c; Brasil, 2015a).

Nos casos em que o local da despesca for contíguo à área do estabelecimento processador e ambos pertençam à mesma pessoa jurídica, no caso de transporte de animais aquáticos com a finalidade de abate não será emitida a GTA, mas o transporte ficará condicionado à emissão de Formulário de Origem do Pescado e do Boletim de Produção (Brasil, 2015a), que contém dados de importância para vigilância epidemiológica dos sistemas de produção e seu preenchimento é de responsabilidade do produtor rural, o responsável técnico do estabelecimento e/ou profissional legalmente habilitado a emitir o referido boletim.

A IN nº 09, de 02 de julho de 2013, trata especificamente do transporte de Caranguejo-Uçá nos estados do Pará, Maranhão, Piauí e Ceará. Esta IN disciplina que para o transporte destes animais, as pessoas físicas ou jurídicas devem ter o cadastro no Instituto Brasileiro do Meio Ambiente e dos Recursos Naturais Renováveis (IBAMA) e os animais devem ser transportados guardando os princípios de bem estar animal. Para o transporte terrestre, os animais devem ser acomodados em caixas plásticas vazadas e forradas com espuma embebida em água. Já para o transporte aquaviário, os animais devem ser acondicionados em caixas plásticas vazadas, sacos, paneiros, peras ou acomodações que garantam a sobrevivência dos mesmos (Brasil, 2013b).

Caberá aos órgãos executores estaduais estabelecer estratégias pautadas na vigilância e risco epidemiológico para a fiscalização do transporte de animais aquáticos vivos, seu material de multiplicação, seus subprodutos e matérias primas (Brasil, 2015a).

\section{Normativas estaduais}

De acordo com a Associação Brasileira da Piscicultura, o Maranhão é o segundo estado que mais cresce na produção de peixes de cultivo em todo o Brasil. Entre os anos de 2017 e 2018, o aumento foi de 47,4\%. Isso fez com que o Estado passasse da $10^{\mathrm{a}}$ para a $6^{\mathrm{a}}$ colocação no ranking dos maiores produtores nacionais. Com a economia em ampla expansão, tornase necessária a criação ou reformulação de legislações destinadas aos fatores ligados direta e indiretamente, aos organismos aquáticos no Estado (Peixe BR, 2020a).

No estado, a Lei no 8.089, regulamenta a Política Estadual de Desenvolvimento da Pesca e da Aquicultura, que tem por princípio básico a prevalência do interesse público, no desenvolvimento sustentável das atividades pesqueiras, como forma 
de promoção de programas de inclusão social, de geração de emprego e renda e de realização do potencial econômico do estado (Maranhão, 2004).

Com a necessidade de reformulação da Política Nacional da Agricultura Familiar e Empreendimentos Familiares Rurais, a Secretaria de Estado do Meio Ambiente e Recursos Naturais do Maranhão (SEMA-MA), por meio da Portaria ${ }^{\circ}$ 10, de 17 de janeiro de 2013, instituiu o processo de simplificação ou dispensa do Licenciamento Ambiental de empreendimentos de piscicultura de pequeno porte para produtores familiares enquadrados no Programa Nacional de Fortalecimento da Agricultura Familiar (PRONAF) e Programas afins (Maranhão, 2013).

Com o passar dos anos e tendo em vista o potencial do estado para a produção do camarão cultivado, considerado o maior de todo o Brasil, novos ideais econômicos deram formação a Lei n ${ }^{\circ}$ 10.421, que institui o Plano de Desenvolvimento da Carcinicultura do Maranhão, concebido e estruturado para que as ações de promoção e fomento da carcinicultura atuem como uma nova força propulsora do desenvolvimento regional, dentro de um horizonte de tempo de dez anos para sua execução (Maranhão, 2016b, 2017a).

Em 2017, a Lei no 10.757 criou o Programa Mais Produção e Abastecimento, vinculado às ações do Sistema Estadual de Produção e Abastecimento (SEPAB), com finalidades indispensáveis o aumento e a otimização da produção agropecuária no Maranhão, agregando valor aos produtos locais e gerando riqueza, emprego e renda, tendo como uma das atividades principais, o pescado. As atividades desenvolvidas neste Programa são coordenadas pela Secretaria de Estado da Agricultura, Pecuária e Pesca (SAGRIMA) que é a responsável pela execução do conjunto de ações integradas na agricultura, pecuária, pesca, aquicultura e abastecimento no território estadual (MARANHÃO, 2017b).

Já em 2020, o Decreto n 35.849 incluiu o pescado, oriundo da agricultura familiar, no cardápio da alimentação escolar das instituições públicas de ensino do estado do Maranhão, obrigatoriamente uma vez por semana, no mínimo, visando estimular a alimentação saudável (Maranhão, 2020b).

\section{Considerações Finais}

No estado do Maranhão a atividade aquícola tem reconhecida importância econômica. Em âmbito nacional, o estado obteve o segundo maior crescimento na produção de peixes de cultivo, alcançando quinto lugar em peixes de cultivo e o terceiro lugar em produção de peixes nativos no ano de 2019.

Porém, ao se analisar o tema vigilância epidemiológica de animais aquáticos, que contempla aspectos fundamentais para o sucesso da atividade aquícola, observa-se que o tema ainda é pouco explorado no país, em que os instrumentos sanitários regulatórios não estão consolidados e tampouco são utilizados na rotina da produção. Atualmente, considera-se escasso o registro de doenças que acometem animais aquáticos no país e, no estado do Maranhão, estes registros são praticamente inexistes.

Para se alcançar níveis aceitáveis de vigilância na aquicultura maranhense, se faz necessário normatizar a legislação estadual, instituindo temas como educação sanitária voltada às comunidades produtoras assim como a educação continuada aos técnicos de municípios com maiores produções, com fins específicos da prática de notificação de enfermidade, atendimento imediato, coleta de materiais e diagnóstico. É necessário que esta legislação estadual ainda contemple a definição, normatização e plano de implantação de medidas de biosseguridade (para evitar e/ou disseminar doenças), assim como a regulamentação de amostragens para diagnóstico de enfermidades de caráter obrigatórias no abate, e também, estimulação as boas práticas de manejo para o aquicultor.

Além da necessidade de estruturação legal e considerando a capacidade da produção estadual e suas potencialidades para exportação, é crucial o estímulo ao sistema de inspeção, que implante processos de controle de procedimentos como Boas 
Práticas de Fabricação (BPF), Procedimento Padrão de Higiene Operacional (PPHO) e de Análise de Perigos e Pontos Críticos de Controle (APPCC), bem como, a adoção de sistemas de autocontrole pelas unidades produtoras, visando o acompanhamento da produção por meio da realização de inspeções e auditorias.

Em síntese, entende-se que os programas sanitários devem ser potencializados, pela magnitude e potencial de crescimento da piscicultura, e sendo o estado do Maranhão um dos maiores produtores da região Nordeste, alguns diagnósticos de rotina devem ser estimulados na produção dos organismos aquáticos, considerando a vigilância de enfermidades ser primordial para toda a cadeia produtiva e sua movimentação.

Portanto, como forma de propor medidas para diminuir os prejuízos econômicos em toda a cadeia produtiva, entendem-se como indispensáveis: priorizar pesquisas com organismos aquáticos; promover a integração entre os especialistas relacionados à defesa animal e inspeção sanitária, visando ampliar o universo sanitário a ser construído no Estado; definir e implantar medidas de biosseguridade nas propriedades de produção, como a adoção de quarentenas para animais introduzidos, os cuidados com utensílios de outras propriedades; bem como, orientar boas práticas de manejo para o piscicultor.

É necessário ainda, melhorar o planejamento da produção para o crescimento de organismos aquáticos no estado, levando em consideração a organização do setor, sua adequação para um futuro próximo e promissor, por meio de interações entre os órgãos de fomento, parcerias com entidades de ensino, proporcionando a extensão rural e aprimoramento da defesa agropecuária, e assim, estar preparado para aberturas de novos mercados (local, estadual ou nacional), bem como para atender às possíveis demandas de exportação que surgem quando há organização da cadeia produtiva.

Espera-se que o presente estudo possa contribuir com a aquicultura maranhense e como uma fonte atualizada de informações acerca da temática estudada. Com base nas funcionalidades propostas nesta pesquisa, sugere-se para trabalhos futuros, o cadastramento dos estabelecimentos aquícolas no estado do Maranhão, realização de vigilância ativa nas propriedades, sensibilização dos aquicultores sobre a importância da notificação de doenças ao órgão de defesa estadual e levantamento das principais doenças (bacterianas, virais, parasitárias e micóticas) que acometem as criações.

\section{Referências}

Almeida Z S, Ferreira D S C \& Nahum V J I. (2006). Classificação e evolução das embarcações maranhenses. Boletim do Laboratório de Hidrobiologia, 19, $31-40$.

Almeida Z S, Silva C M L, Cavalcante N A, Paz A C, Santos N B \& Gonçalves F S. (2207). Contribuição à conservação e manejo do Peixe Serra Scomberomorus brasiliensis (Collette Russo \& Zavalla-Camin, 1978) (Osteichtyes, Scombridae) no Estado do Maranhão, Brasil. Boletim Técnico Científico CEPENE, Tamandaré, 15(2), 87-9.

Alves J M C. (2020). Mercado registra aumento de consumo e de produção de pescado, peixes e camarões. Mas como ficará a situação pós-Covid-19?. Revista panorama da Aqüicultura. http://panoramadaaquicultura.com.br/mercado-registra-aumento-de-consumo-e-producao-como-ficara-situacao-pos-covid-19/

Brabo M F, Pereira L F S, Santana J V M, Campelo D A V \&Veras G C. (2016). Cenário atual da produção de pescado no mundo, no Brasil e no estado do Pará: ênfase na aquicultura. Acta of Fisheries and Aquatic Resources, 4(2), 50-58.

Brasil. (2003). Ministério da Agricultura, Pecuária e Abastecimento. Instrução Normativa no 53, de 2 de julho de 2003. Aprova o Regulamento Técnico do Programa Nacional de Sanidade de Animais Aquáticos. http://www.icmbio.gov.br/cepsul/images/stories/legislacao/Instrucao _normativa/2003/in_mapa_53_2003_regulamentotecnico_programanacionalsanidade_animaisaquaticos.pdf.

Brasil (2012). Ministério da Pesca e Aquicultura. Instrução Normativa no 03, de 13 de abril 2012. Institui a Rede Nacional de Laboratórios do Ministério da Pesca e Aquicultura - RENAQUA, responsável pela realização de diagnósticos e análises oficiais, bem como o desenvolvimento contínuo de novas metodologias analíticas. http://www.gov.br/agricultura/pt-br/assuntos/sanidade-animal-e-vegetal/saude-animal/programas-de-saude-animal/arquivosprogramas-sanitarios/INN3DE13042012.pdf. Acesso em: 15 set. 2020.

Brasil. (2013a). Ministério da Pesca e Aquicultura. Instrução Normativa no 10, de 11 de julho de 2013. Institui a Rede de Colaboração em Epidemiologia Veterinária do Ministério da Pesca e Aquicultura. http://www.aged.ma.gov.br/files/2017/03/IN_n_10_2013_MPA_AQUAEPI.pdf.

Brasil. (2013b). Ministério da Pesca e Aquicultura. Instrução Normativa $n^{\circ}$ 9, de 2 de julho de 2013. Dispõe sobre normas e padrões para o transporte de caranguejo-uçá, Ucides cordatus, nos estados do Pará, Maranhão, Piauí e Ceará. http://www.gov.br/agricultura/pt-br/assuntos/aquicultura-epesca/legislacao/caranguejo/instrucao-normativa-mpa-no-09-de-02-de-julho-de-2013.pdf. 
Brasil. (2014a). Ministério da Pesca e Aquicultura. Instrução Normativa $n^{o}$ 26, de 12 de novembro de 2014. Estabelece normas para habilitação de profissionais privados para a realização de coleta e remessa de amostras oficiais para laboratórios da Rede Nacional de Laboratórios do Ministério da Pesca e Aquicultura - RENAQUA e dá outras providências. http://www.aged.ma.gov.br/files/2017/03/IN_n_26_2014_MPA_Habilitacao_ coleta_amostras_oficiais.pdf.

Brasil. (2014b). Ministério da Pesca e Aquicultura. Instrução Normativa no 23, de 11 de setembro de 2014. Determinar a obrigatoriedade da Guia de Trânsito Animal (GTA) para amparar o transporte de animais aquáticos vivos e matéria-prima de animais aquáticos provenientes de estabelecimentos de aquicultura e destinados a estabelecimentos registrados em órgão oficial de inspeção e aprova o modelo de Boletim de Produção. http://www.aged.ma.gov.br/files/2017/03/IN_n_23_de_11_09_2014_Obrigatoriedade_da_GTA.pdf.

Brasil. (2014c). Ministério da Pesca e Aquicultura. Instrução Normativa $n^{o}$ 4, de 30 de maio de 2014. Estabelecer a Nota Fiscal do pescado, proveniente da atividade de pesca ou de aquicultura, como documento hábil de comprovação da sua origem para fins de controle de trânsito de matéria-prima da fonte de produção para as indústrias beneficiadoras sob serviço de inspeção. http://www.icmbio.gov.br/cepsul/images/stories/ legislacao/Instrucao_normativa/2014/ini_mpa_mapa_04_2014_nota_fiscal_pescado.pdf.

Brasil. (2015a). Ministério da Pesca e Aquicultura. Portaria nº 19, de 04 de fevereiro de 2015. Define a lista de doenças de notificação obrigatória de animais aquáticos ao Serviço Veterinário Oficial (SVO). http://www.gov.br/agricultura/pt-br/assuntos/sanidade-animal-e-vegetal/saude-animal/programas-de-saudeanimal/arquivos-programas-sanitarios/PortariaMPAn19de04.02.2015Listadedoenasdenotificaoobrigatriadeanimaisaquticos.pdf.

Brasil. (2015b). Ministério da Agricultura, Pecuária e Abastecimento. Instrução Normativa ${ }^{\circ}$ 04, de 4 de fevereiro de 2015. Institui o programa nacional de sanidade de animais aquáticos de cultivo - Aquicultura com Sanidade. http://www.in.gov.br/materia/-/asset_publisher /Kujrw0TZC2Mb/content/id/32382246/do1-2015-02-09-instrucao-normativa-n-4-de-4-de-fevereiro-de-2015-32382233.

Brasil. (2017). Ministério da Agricultura, Pecuária e Abastecimento. Aquicultura brasileira cresce 123\% em dez anos. http://www.gov.br/agricultura/ptbr/assuntos/noticias/aquicultura-brasileira-cresce-123-em-dez-anos. Acesso em 05 jul. 2020.

Brasil. (2019a). Ministério da Agricultura, Pecuária e Abastecimento. Pesca no Brasil. Brasília, 14 mar. 2019b. https://www.gov.br/agricultura/ptbr/assuntos/aquicultura-e-pesca/pesca/pesca-no-brasil.

Brasil. (2019b). Ministério da Agricultura, Pecuária e Abastecimento. Anuário dos Programas de Controle de Alimentos de Origem Animal do DIPOA. http://antigo.agricultura.gov.br/assuntos/inspecao/produtos-animal/arquivos-publicacoes-dipoa/anuario-v-5-2019-versao-final-aprovada.pdf/view.

Brasil. (2019c). Ministério da Agricultura, Pecuária e Abastecimento. Sanidade dos animais Aquáticos. 2019d. http://www.gov.br/agricultura/ptbr/assuntos/sanidade-animal-e-vegetal/saude-animal/programas-de-saude-animal/sanidade-dos-animais-aquaticos\#: :text=O\%20Programa\%20Nacional $\% 20$ de $\% 20$ Sanidade,a\%20partir\%20dos\%20cultivos\%20nacionais.

Brasil. (2019d). Ministério da Agricultura, Pecuária e Abastecimento. Instrução Normativa $n^{o}$ 04, de 28 de fevereiro de 2019. Altera a Instrução Normativa ${ }^{\circ}$ 4, de 04 de fevereiro de 2015. http://www.gov.br/agricultura/pt-br/assuntos/sanidade-animal-e-vegetal/saude-animal/programas-de-saude-animal/arquivosprogramas-sanitarios/INMAPAn4de28.02.2019AlteraaINMPA042015.pdf.

Brugere C, Onuigbo D M \& Morgan K L. (2017). People matter in animal disease surveillance: challenges and opportunities for the aquaculture sector. Aquaculture, 467, 158-169. http://www.sciencedirect.com/science/article/pii/S0044848616301983?via\%3Dihub\#bbb0690.

Fogaça F. (2020). O Brasil e a produção mundial de pescado: país ocupa apenas a $13^{a}$ posição na criação de peixes em cativeiro e é o $8^{\circ}$ na produção de peixes de água doce. Revista Globo Rural. https://revistagloborural.globo.com/Noticias/Opiniao/noticia/2020/07/o-brasil-e-producao-mundial-de-pescado.html.

Freire M V C, Sales Júnior R A, Costa M G A \& Ferreira L. (2019). Transporte de organismos aquáticos: procedimento fundamental para desenvolvimento da aquicultura. Pubvet, 13(10), 1-10, out. 2019.

Gerhardt T E \& Silveira D T. (2009). Métodos de Pesquisa. Editora da UFRGS.

Goes G A, Oliva R A, Ronqui R G, Queiroz T R \& Satolo E G. (2017). Descrição do sistema logístico de transporte: uma análise conceitual envolvendo piscicultura. South American Development Society Journal, 1(2), 100-115. http://www.sadsj.org/index.php/revista/article/view/16.

Halliday J, Daborn C, Auty H, Mtema Z \& Lembo T, Bronsvoort BM, Handel I, Knobel D, Hampson K e Cleaveland S. (2012). Bringing together emerging and endemic zoonoses surveillance: shared challenges and a common solution. Philosophical Transactions of the Royal Society B: Biological Sciences, $367(1604), 2872-2880$.

Kirchner R M, Chaves M A, Silinske J, Essi L, Scherer M E \& Durigon E G. (2016). Análise da produção e comercialização do pescado no Brasil. Revista Agro@mbiente On-line, 10, 168-177.

Leira M H, Reghim L S, Ciacci L S, Cunha L T, Botelho H A, Braz M S, Dias N P \& Melo, C C V. (2017). Problemas sanitários das pisciculturas brasileiras. Pubvet, 11(6), 538-544

Maciel M L T \& Maciel C T A. (2011). Construção institucional e organizacional do serviço de defesa sanitária animal no Estado de Santa Catarina com vistas à sanidade dos bivalves marinhos. Revista de Ciências Agroveterinárias, 10(2), 138-144.

Martins A M C R.P F, Hipolito M \& Catroxo M H. (2011). A importância da piscicultura e algumas doenças virais e bacterianas písceas. Instituto Biológico de http://www.biologico.sp.gov.br/publicacoes/comunicados-documentos-tecnicos/comunicados-tecnicos/a-importancia-da-piscicultura-e-algumas-doencasvirais-e-bacterianas-pisceas.

Maranhão. (2004). Lei $n^{\circ} 8.089$, de 25 de fevereiro de 2004. Dispõe sobre a Política Estadual de desenvolvimento da pesca e da aquicultura e dá outras providências. Diário Oficial do Estado do Maranhão, Poder Executivo, São Luís, MA, 060, 1-6. 
Maranhão. (2013). Secretaria de Estado do Meio Ambiente e Recursos Naturais do Maranhão - SEMA. Portaria SEMA $n^{o} 10$, de 17 de janeiro de 2013. Institui o processo de simplificação ou dispensa do Licenciamento Ambiental de empreendimentos de piscicultura de pequeno porte para produtores familiares enquadrados no PRONAF e Programas afins. http://www.legisweb.com.br/legislacao/?id=250795.

Maranhão. (2016a). Secretaria de Estado da Agricultura do Maranhão - SAGRIMA. Agência Estadual de Defesa Agropecuária do Maranhão. Anuário 2015: ações de defesa sanitária agropecuária no Maranhão. https://www.aged.ma.gov.br/files/2017/08/ANU\%C3\%81RIO-2015-Final-18mai2016.pdf.

Maranhão. (2016b). Lei $n^{\circ} 10.421$, de 21 de março de 2016. Dispõe sobre o fomento a proteção e a regulamentação da carcinicultura, reconhecendo-a como atividade agrosilvipastoril, de relevante interesse social e econômico, estabelecendo as condições para o seu desenvolvimento sustentável no Estado do Maranhão, para o que dá outras providências. http://abccam.com.br/wp-content/uploads/2016/03/LEI-DA-CARCINICULTURA-maranh\%C3\%A3o-1.pdf.

Maranhão. (2017a). Secretaria de Estado da Agricultura, Pecuária e Pesca - SAGRIMA. Plano de Desenvolvimento da Carcinocultura do Maranhão: com atualização dos dados econômicos e dos programas de incentivo governamental aos investimentos. http://sagrima.ma.gov.br/files/2017/08/PLANO-DECARCINICULTURA.pdf.

Maranhão. (2017b). Lei $n^{\circ}$ 10.757, de 19 de dezembro de 2017. Dispõe sobre o Programa Mais Produção e Abastecimento e dá outras providências. http://stc.ma.gov.br/legisla-documento/?id=5047.

Maranhão. (2020a). Agência Estadual de Defesa Agropecuária - AGED/MA. Sanidade dos Animais Aquáticos (Aquicultura com Sanidade). http://www.aged.ma.gov.br/sanidade-dos-animais-aquaticos-aquicultura-com-sanidade/.

Maranhão. (2020b). Decreto $n^{\circ} 35.849$, de 25 de maio de 2020. Dispõe sobre a inclusão no cardápio da alimentação escolar das instituições públicas de ensino do Estado do Maranhão, e dá outras providências. https://www.diariooficial.ma.gov.br/public/index.xhtml.

Oidtmann B C, Thrush M A, Denham K L \& Peeler E J. (2011). International and national biosecurity strategies in aquatic animal health. Aquaculture, 320(12), 22-33.

Organización Mundial de Sanidad Animal. (2019a). Código sanitário para los animales acuáticos. Prevención y control de las enfermidades. Título 4. http://www.oie.int/es/normas/codigo-acuatico/acceso-en-linea/.

Organización Mundial de Sanidad Animal. (2019b). Código sanitário para los animales acuáticos. Notificación de enfermidades y aportación de datos epidemiológicos. Capítulo 1.1. http://www.oie.int/index.php?id=171\&L=2\&htmfile=chapitre_notification.htm.

Pedroza M \& Rocha H. (2020). Informativo de Comércio Exterior da Piscicultura, Trimestre 01/2020 - Exportações da piscicultura brasileira no $1^{\circ}$ trimestre de 2020. Embrapa Pesca e Aquicultura. http://www.embrapa.br/documents/1355321/52258293/primeiro+trimestre+2020/fdd0bd4c-1424-7b61-4de3ceb9acc9497c.

Peixe BR - Associação Brasileira de Piscicultura. (2020a). Anuário da Piscicultura 2020. Lançamento anuário peixe BR de piscicultura 2020. http://www.peixebr.com.br/lancamento-anuario-peixe-br-de-piscicultura-piscicultura-2020/.

Peixe BR - Associação Brasileira de Piscicultura. (2020b). Exportações de peixes de cultivo aumentam 32,8\% no $1^{\circ}$ trimestre de 2020. http://www.peixebr.com.br/exportacoes-de-peixes-de-cultivo-aumentam-328-no-1o-trimestre-de-2020/.

Peixe BR - Associação Brasileira de Piscicultura. (2020c). Anuário da Piscicultura 2020. Produção de peixes nativos inverte tendência e ensaia crescimento .http://www.peixebr.com.br/anuario-2020/. Acesso em: 06 jul. 2020.

Rodgers C J, Carnegie R B, Chávez-Sánchez M C, Martínez-Chávez C C \& Hine P M. (2015). Legislative and regulatory aspects of molluscan health management. Journal of Invertebrate Pathology, 131, 242-255. http://www.sciencedirect.com/science/article/abs/pii/S0022201115001226.

Santiago J A S, Araújo P F R, Santiago A P, Carvalho F C T \& Vieira R H S F. (2013). Bactérias patogênicas relacionadas à ingestão de pescados: revisão. Arquivos de Ciência do Mar, 46(2), 92-103.

Santos M. (2018). Fauna parasitária em tambaqui (Colossoma macropomum) provenientes de cinco pisciculturas do município de Rorainópolis-RR. Trabalho de Conclusão de Curso em Zootecnia. Monografia.

Sartori A G O \& Amancio R D. (2012). Pescado: importância nutricional e consumo no Brasil. Revista de Segurança Alimentar e Nutricional, 19(2), 83-93

Zhiming Z, Chao D, Chuanfu D, Shaoping W \&Jianguo H. (2020). Epidemiological situation and phylogenetic relationship of Vibrio harveyi in marinecultured fishes in China and Southeast Asia. Aquaculture, 529, 735652. 